\title{
UNA EXPERIENCIA ESTUDIANTIL Y COLECTIVA DE INVESTIGACIÓN FEMINISTA DECOLONIAL EN LA UNIVERSITAT DE VALÈNCIA. TRAYECTORIAS EPISTÉMICAS Y METODOLÓGICAS
}

\section{A student and collective experience of decolonial feminist research at the University of Valencia. Epistemic and methodological trajectories}

\author{
Salomé Carvajal Ruiz \\ salome.carvajalruiz@gmail.com \\ Universitat de València - España
}

Recibido: 28-02-2017

Aceptado: 03-06-2017

\section{Resumen}

Necesitábamos producir conocimientos situados y llevar a cabo prácticas feministas al margen de las epistemes eurocéntricas y metodologías positivistas aprendidas en las aulas universitarias en favor de querer-hacer-vivir feminismos no hegemónicos. Nos propusimos crear y dinamizar una Colectiva como estrategia de participación universitaria sociocultural que sostuviera una complementariedad dinámica tanto epistemológica como metodológica. El presente texto narra parte de la trayectoria de la Colectiva como locus propicio para llevar a cabo una experiencia colectiva de investigación estudiantil liderada por mujeres-migrantes-racializadas-estudiantes de la Universitat de València, compartiendo y conviviendo trayectorias feministas que devinieron inexcusablemente decoloniales.

Palabras clave: Investigación feminista decolonial, participación universitaria, mujeres migrantes, mujeres racializadas.

\begin{abstract}
We needed to produce situated knowledges and undertake feminist practices, apart from the eurocentric episthemes and positivist methodologies learned in university classrooms, with the aim to want-do-live non-hegemonic feminisms. We intended to create and energize a Collective as a strategy for sociocultural university participation which could support a dynamic complementarity both episthemological and methodological. The present paper narrates part of the trajectory of the Collective as a favorable locus to bring about a collective experience of student research lead by migrant-racialized-student-women from University of Valencia, sharing and living altogether feminist trajectories which became inexcusably decolonial.
\end{abstract}

Keywords: Decolonial feminist research, university participation, migrant women, racialized women. 


\section{Introducción}

El texto narra parte de las experiencias vividas y compartidas entre mujeres migrantes racializadas estudiantes de la Universitat de València que decidimos llevar a cabo investigaciones y praxis feministas junto con mujeres de un barrio popular de la ciudad de la ciudad de Valencia a través de una estrategia de participación universitaria y sociocultural en la creación y dinamización de la Colectiva Tierrosas entre los años 2014 y 2016.

Como experiencia inspirada en otras epistemologías y metodologías alternativas a las aprendidas en la universidad concretamente en el Sumak Kawsay o también llamado buen vivir y a sabiendas de las limitaciones que implican las aproximaciones, el peligro del expolio de saberes y prácticas procedentes de Abya Yala nos encaminamos en la construcción de ese imposible.

Se parte por presentar a la Colectiva Tierrosas, para dar paso a las Problematizaciones y reflexiones en torno a la pregunta ¿Qué vida queremos convivir?, la misma que articuló las cinco dislocaciones que nos acometían y que hemos sistematizado como: a) dislocación identitaria, b) dislocación individualista c) dislocación antropocentrista y androcentrista, d) dislocación relacional e) dislocación colonial.

Se emplean las apachetas como figura andina que inspiran a cruzar los caminos construyendo bagajes materiales, simbólicos, espirituales, ecológicos, etc. Las apachetas representan a los momentos y acciones compartidas en la convivencia y que involucran a todas las participantes y fueron: a) apacheta encuentros comunes b) apachetas cuerpos-territorio c) apacheta rituales y artificios.

Finamente se expone brevemente la matriz filosófica de las evaluaciones-estimaciones -sin concluir- desarrolladas en base a: yachay, munay, ushay, ruray, cuatro fuentes del sumak kawsay.

Tierrosas fue un locus de investigación configurado por los encuentros, lugares, comidas, rituales, afectos, y además "otras relaciones" que no son susceptibles de escribir ni de leer. En el texto no se desarrolla toda la experiencia sino parte de las trayectorias epistémicas y metodológicas de producción de conocimientos y praxis situadas.

\section{La Colectiva Tierrosas}

Considérese a Tierrosas como un locus propicio para la descolonización y despatriarcalización de los feminismos aprendidos en las aulas universitarias. Una estrategia 
estudiantil nacida y liderada por mujeres-migradas-racializadas ${ }^{1}$-estudiantes de la Universitat de València y mayoritariamente de orígenes latinoamericanos que decidimos llevar a cabo investigaciones feministas inspiradas en los saberes, cosmovisiones y experiencias políticas de los feminismos de Abya Yala², entre el 2014-2016.

Para aprender otros feminismos alternativos a los hegemónicos nos dispusimos a imaginar, crear, construir una micropolítica para buen vivir ${ }^{3}$, con una metodología basada en la investigación militante que permitiera articular distintas opresiones por género, clase, raza, procedencia, nacionalidad a las que llamamos dislocaciones. A la vez que identificamos malestares específicos nos dimos cuenta de la potencialidad de repensar y resignificar nuestras prácticas, las relaciones entre nosotras, con la Naturaleza, en nuestros entornos y cada una en sí misma.

Parte de la investigación consistió en decidir por otras epistemologías cuidando de no realizar idealizaciones y expolios de los saberes y experiencias situadas en Abya Yala sino dejarse inspirar por las mismas. De esta manera construimos unas espitemologías representadas gráficamente al ojo de las personas como un entramado multidimensional y multicolor capaz de dejar pensar-sentir-ver al patriarcado, al colonialismo y al capitalismo en sus entronques y enmarañados.

Tierrosas como locus (educativo, político, ético, estético, ecológico) nació como una estrategia estudiantil universitaria sustentada en las desesidades ${ }^{4}$ individuales y colectivas de querer-hacer feminismos ligados a las experiencias migratorias de mujeres.

Con el tiempo, la experiencia y la cercanía con mujeres, niñas y niños, en su mayoría de orígenes latinoamericanos, nos dimos cuenta que la despatriarcalización y la descolonización no podíamos hablar-hacer-sentir desde miradas que distancian y jerarquizan a las personas como objetos-sujetos. Nos vimos en la necesidad de superar las limitaciones de los registros lingüísticos formales aprendidos en las aulas universitarias para poder conversar fluidamente por ejemplo de patriarcado, globalización, racismo, precariedad, etc., en encuentros para el recíproco entendimiento, festivos y rituales.

\footnotetext{
${ }^{1}$ Entiéndase mujeres racializadas como la construcción eurocéntrica discursiva histórica, social, ontológica que adscribe a ciertas personas a categorías fijas en términos raciales dando como consecuencia complejos procesos de identificación y diferenciación de acuerdo a fenotipos, criterios lingüísticos, procedencias, cosmovisiones, etc.

${ }^{2}$ Abya Yala "es el nombre kuna que ese pueblo utiliza para nombrar tanto a las tierras al norte como a las tierras al sur de su territorio ancestral, en el Istmo de Panamá e islas circunvecinas. El movimiento de los pueblos indígenas suramericanos y centroamericanos lo han adoptado como un nombre no colonial de América, con el que identifican la totalidad de los territorios donde viven 607 o más pueblos originarios". (Gargallo, 2014: 156)

${ }^{3}$ El Buen Vivir recupera la cosmovisión andino-amazónica de Sumak Kawsay (en lengua kichwa) o Suma Qamaña (en lengua aymara). Podría entenderse como vida buena, vivir bien, vida armoniosa, tierra sin mal. Dadas las problemáticas, posibilidades y limitaciones de sumak kawsay/suma qañama en nuestros contextos, acudimos a referentes que ponen a la sostenibilidad de la vida en el centro: "hablamos de buen vivir para referirnos a una (futura) noción ética y políticamente codificada de vida que merece ser vivida que sea el resultado de una discusión radicalmente democrática" (Pérez Orozco, 2014: 228-229).

${ }^{4}$ La palabra desesidades rompe con la oposición deseo/necesidad fusionándolas.
} 
Uno de los mayores aprendizajes fue la urgencia de "volver a los orígenes" y no como nostalgia migratoria sino como un modo de activación micropolítica de la memoria histórica entre personas migradas y las/los descendientes para conocernos y cuidarnos a nosotras mismas en los actuales entornos de convivencia. Entre estos y otros motivos la Colectiva Tierrosas no emerge como una investigación feminista decolonial, deviene en ello inexcusablemente.

\section{Un problema articulado: Problematización y reflexiones}

El planteamiento de una pregunta vectora de investigación nos permitió articular otras preguntas y problematizar las distintas opresiones por género, clase social, nacionalidad, procedencia, raza vividas. Poniendo a la sostenibilidad de la vida en el centro de nuestra micropolítica fuimos preguntándonos ¿Qué vida queremos con-vivir?

Ajenas a la supuesta neutralidad en el quehacer investigador y sin pretender poner en marcha metodologismos protocolizados apostamos por la investigación militante como un viaje abierto: "por encima de cualquier método, están las operaciones reales que el proceso de investigación militante es capaz de poner en marcha. La investigación militante es, en este sentido, siempre, un viaje abierto, que sabemos de dónde y cómo parte, pero no adónde nos llevará” (Malo, 2004: 35).

En la investigación como viaje abierto nos dimos cuenta de la complejidad de las cuestiones identitarias que nos atravesaban, de las fauces del individualismo, de las ajenidades recíprocas y con la Naturaleza, del racismo vivido, del trabajo fuera-dentro de casa, del cuidado y crianza de las hijas e hijos, del amor, de "las raíces", etc., por eso planteamos a modo de dislocaciones que sistematizamos teóricamente.

Cabe decir que muchas cuestiones que evidencian las especificidades de las opresiones de las mujeres y de las niñas y niños migrantes y racilizadas con las que convivimos no se han plasmado por escrito en este texto, no se han olvidado ni negado, pero tampoco pueden ser aprehendidas bajo el mandato de la escritura y la lectura, han sido sentidas, vividas en realidades meta-racionales.

\section{1. Dislocación identitaria: identidades en los cruces de caminos}

En los distintos conversatorios-taller surgieron momentos de reflexión profunda acerca de las identidades. La categoría "mujeres migrantes" debió ampliarse frente a las múltiples circunstancias que nos acometían. Reconocernos mujeres, migrantes, de diferentes países y territorios latinoamericanos, trabajadoras, algunas estudiantes, algunas madres, algunas con parejas, etc., conviviendo entre las diferencias, pero encontrándonos en discriminaciones comunes. 
Nos dimos cuenta que la procedencia, la nacionalidad, la clase social, la racialización, etc., configuraban un complejo entramado en la construcción y sentido de sí misma y de nosotras por tanto en nuestras cuestiones identitarias. Los cuerpos racializados, los trabajos desempeñados en su mayoría en servicio doméstico con largas jornadas, precarias retribuciones económicas, incluso en la esclavitud disfrazada de trabajo regulado con la insignia de "régimen interno", el régimen de esclavitudes modernas, las experiencias burocráticas de tramitar los permisos de residencia y trabajo, los modos de hablar y entonar extranjerizados, y un largo etc. En algunas ocasiones nos sentimos semejantes y otras no.

Muchas de nosotras nos sentimos cómodas resignificando nuestras identidades mestizas en el contexto valenciano, acercándonos a las reflexiones que Gloria Anzaldúa poetizó con tanta sensibilidad en la Nueva Mestiza cuando se vive en el cruce de caminos:

"No eres hispana india negra española

ni gabacha, eres mestiza, multa, media casta

atrapada en el fuego cruzado entre los bandos

mientras cargas las cinco razas a tu espalda

sin saber a qué lado volverte, de cuál huir" (Anzaldúa, 2016:216).

En ciertos momentos, el lugar de procedencia fue uno de los factores identitarios más relevantes y valiosos para autodefinir las identidades rompiendo de cierto modo con los estereotipos de mujeres pobres, sin culturas, venidas para servir a la población oriunda, mujeres sumisas, sexualizadas y cariñosas pese a cualquier tipo y grado de violencia.

Hablar de los orígenes y compartirlos a través de los recuerdos, las comidas, los cuentos e hsitorias, etc. formó parte de la desvictimización encarnada ante los discursos asistenciales, paternalistas y racistas que se han ido generando a través de los medios de comunicación y también en el seno de las instituciones gubernamentales y organizaciones no gubernamentales, incluso en sectores "progresistas" y de "izquierdas".

Actualmente, seguimos desarrollando investigaciones encarnadas para conocernos y cuidarnos mejor recuperando la memoria histórica tan compleja y pluridiversa y en clave decolonial para darle valor en nuestros contextos. Continuamos apostando por repensarnos en contraposición de las representaciones etno y eurocéntricas y las limitaciones impuestas por la colonialidad del saber, del poder, del ser y del género.

\subsection{Dislocación individualista: una comunidad recíproca}

En el feminismo comunitario, la comunidad, es una de las categorías políticas, éticas y ecológicas más importantes. Es más que un modo de estar porque funciona como una racionalidad alternativa frente al pensamiento moderno occidental y en las mareas neoliberales. Desembarazada del desprecio y estigma moderno, la comunidad, está formada por las personas, 
pero también los espacios, los momentos, los cuerpos-territorios, la Naturaleza, las relaciones, etc. todas y todos forman parte de un mismo cuerpo:

"La comunidad es como un cuerpo, nosotras las mujeres somos la mitad de ese cuerpo que es la comunidad, la otra mitad son los hermanos hombres, en medio están las personas intersexuales. Un ojo, una mano, un pie, un lado del cuerpo son los hombres, el otro ojo, la otra mano, el otro pie, somos nosotras las mujeres. Nuestra lucha es para que todo el cuerpo, que es la comunidad, viva bien. No podríamos cortar, ni partir, con una sierra o con un hacha en dos al cuerpo que es la comunidad, pues la comunidad moriría. Tampoco se trata que un ojo pelee contra el otro ojo, ni un pie contra el otro pie, ni una mano contra la otra mano, cada quien es importante. De lo que se trata es que funcionen los dos ojos, dos pies, dos manos, para que la comunidad vea bien, haga bien, camine bien" (Paredes y Guzmán 2014: 90).

No se trató de idealizar y tampoco de exportar "la comunidad" sino dejarse inspirar por otros modos de relacionarse en y con la vida. Apostamos por imaginar modos comunitarios y horizontales de reciprocidad entre nosotras, con las niñas y niños y en los espacios donde convivimos.

La comunidad para nosotras significó compartir historias, mitos y leyendas, jugar y ejercitarnos al aire libre, hablar de política y economía en un parque infantil ubicado en los Jardines del Río Turia los domingos por la tarde. Hacer valer cada inquietud y proponerla como tema de conversa o experiencia lúdica. La reciprocidad como valor fundamental no se podía medir ni en horas de participación ni en cumplimiento de normas rígidas en el contexto de una investigación. Fue vivida y creada en momentos de libertad, alegría y buen vivir colectivo. Nuestra pequeña comunidad intercultural e intergeneracional procuró una micropolítica de la cercanía entre lo personal y lo político.

\section{3. Dislocación antropocentrista y androcentrista: Pachamama sí, Madre Tierra no}

La Naturaleza no es un mero medio para satisfacer las necesidades humanas ni objeto sujeta a los designios de dominio, control y explotación androcéntricos y antropocéntricos supeditados al capital.

En las culturas originarias de Abya Yala, tanto las agrícolas como las recolectoras, la Naturaleza mantenía una comunicación viva entre los seres que la componen. A día de hoy, diversas culturas siguen preservando las cosmovisiones, cosmogonías, éticas de la suficiencia. Para muchas personas la Naturaleza es como la Madre Tierra con quien se mantienen diálogos permanentes y se construyen complejos entramados culturales e identitarios. La cultura occidental hegemónica en nombre del desarrollo y sostenido por el pensamiento moderno capitalista y patriarcal ha forjado los bienestares humanos sin considerar a la Naturaleza como sujeta de derechos y mucho menos las consecuencias de los ecocidios. 
Nuestras desesidades colectivas estaban dirigidas además a poder-hacer de los Derechos de la Naturaleza $a^{5}$, acciones concretas de vuelta la Tierra, politizando-reconciliando la relación con la misma y a la vez reconociendo que "[...] los derechos de la naturaleza no son únicamente de matriz indígena, resultan de un sincretismo de culturas, conocimientos y saberes" (Martínez Yánez, 2014: 41).

Al hilo de las identidades mestizas, hemos reconocido que los Derechos de la Naturaleza son a su vez una reiteración del mestizaje y el devenir de nuevas identidades, “[...] por una parte recupera elementos propios de la cultura occidental y por otra de las culturas indígenas, además nacen como resultado de un choque de culturas que ha dejado profundas heridas y, a la vez, nuevas identidades" (Martínez Yánez, 2014:11).

Dado el baluarte mestizo de los Derechos de la Naturaleza retomamos a la Pachamama conscientes que desde las culturas fundamentalmente indígenas u originarias de Abya Yala es que se puede entender quién es y qué es. Los términos Pachamama, Sumak Kawsay, Suma Qamaña no pueden ser traducidos con rigor semántico y sintáctico al español, debido a cuestiones como, por ejemplo, la concepción del tiempo lineal en la cultura occidental contraria a la cíclica, espiral de la cultura andina originaria.

Frente a la feminización patriarcal, sexista y machista, utilitariasta moderna de la Naturaleza y además el patriarcado originario que sitúan a la Pachamama como el gran útero productor y reproductor de la vida, optamos por la propuesta del Feminismo Comunitario (2010: n.p. $)^{6}$ :

"Entendemos a la Pachamama, a la Mapu, como un todo que va más allá de la naturaleza visible, que va más allá de los planetas, que contiene a la vida, las relaciones establecidas entre los seres con vida, sus energías, sus necesidades y sus deseos. Denunciamos que la comprensión de Pachamama como sinónimo de Madre Tierra es reduccionista y machista, que hace referencia solamente a la fertilidad para tener a las mujeres y a la Pachamama a su arbitrio patriarcal”.

Más que una terapia de contacto con la Naturaleza, queremos sentir la Pachamama como realidad y relación.

\subsection{Dislocación relacional: Recíprocas}

Cuando nos referimos a la conviencia necesitamos repensar los modos de hablar, de tratarnos, de situar nuestros cuerpos, de resignificar las experiencias como mujeres migradas y

\footnotetext{
${ }^{5}$ La Constitución de la República del Ecuador de 2008, recoge los Derechos de la Naturaleza en el Título VII del Régimen del Buen Vivir, en el capítulo séptimo, en los artículos 71, 72, 73, 74 (Gobierno de Ecuador, 2008). En la Constitución del Estado Plurinacional de Bolivia de 2009 el sumak qañama será uno de los ejes transversales (Gobierno de Bolivia, 2009).

${ }^{6}$ Pronunciamiento del Feminismo Comunitario en Tiquiyapa, en la Cumbre de los Pueblos sobre el Cambio Climático.
} 
racializadas, en relación con nosotras mismas y con la Pachamama para seguir problematizando ¿Qué vida queremos con-vivir?

En pleno auge de discursos de competencias emocionales y de habilidades sociales en las relaciones humanas, nos preguntamos cómo transitar de las ajenidades recíprocas con modos de vivir individualistas y fragmentados hacia otro tipo de relaciones más comunitarias sin disolver las singularidades. Sabemos de los orígenes capitalistas y de matriz moderno occidental de las ajenidades recíprocas: "[...] el capitalismo para poder constituirse en la forma de producción dominante, tenía y tiene que producir permanentemente, no sólo mercancías capitalistas o una forma de agrupación humana que fuese producto de su propia producción y reproducción subjetiva" (Bautista, 2014: 210).

En diálogo con Marx, Bautista (2014) trae a nuestros tiempos las aportaciones hechas por Marx en "El Proceso de Producción del Capital"7 donde se puede leer la crítica a la necesidad del capitalismo de promover una suerte de relaciones sociales, que establecen y activan ajenidades recíprocas destruyendo otros modos relacionales, especialmente las relaciones comunitarias:

"Las cosas, en sí y para sí, son ajenas al hombre y por ende enajenables. Para que esta enajenación sea recíproca, los hombres no necesitan más que enfrentarse implícitamente como propietarios privados de esas cosas enajenables, enfrentándose, precisamente por eso, como personas independientes entre sí. Tal relación de ajenidad recíproca, sin embargo, no existe para los miembros de una entidad comunitaria de origen natural, ya tenga la forma de una familia patriarcal, de una comunidad índica antigua, de un estado inca, etcétera. El intercambio de mercancías comienza donde terminan las entidades comunitarias, en sus puntos de contacto con otras entidades comunitarias o con miembros de éstas” (Marx, citado en Bautista, 2014: 210-211).

Chirrían las palabras de Marx, cuando asevera que la ajenidad reciproca no existe en una entidad comunitaria "de origen natural" como la familia patriarcal. El modelo de familia tradicional patriarcal ha sido objeto de toda suerte de alabanzas y privilegios al considerarla el núcleo de protección, seguridad y socialización de las personas y como célula fundamental de la sociedad. Ha sido nucleada por los estados, las religiones, las ciencias sociales, las propias gentes. Hemos dicho que Tierrosas, pretendía comunidad, pero no formar una familia normativa y menos de modelo tradicional heteropatriarcal occidental.

Históricamente, se ha venido destruyendo, deslegitimando y hasta ridiculizando, aquellas formas de vida comunitaria distintas al modelo de vida social sustentadas por la racionalidad capitalista moderna. Nosotras, encontramos señales inspiradoras para crear la vida que queremos vivir, en el Sumak Kawsay, en el $a y n i^{8}$, la minka como trabajo comunitario donde la plata (el

\footnotetext{
${ }^{7}$ Cfr. Marx, El Capital, cit., pp. 107-108 (Capítulo II, "El proceso de Intercambio)

${ }^{8}$ Ayni es una forma de vida que se origina en los tiempos pre-hispánicos en Abya Yala basadas en la ayuda mutua, reciprocidad, sin ánimo de lucro. Significa ayudar dando la mano en momentos de necesidad, ayuda que será devuelta de alguna manera.
} 
dinero) no es lo que de verdad importa para tratarnos de otras maneras ajenas a la competitividad y soledad neoliberal.

Desde finales del siglo XX pueblos y gentes de Abya Yala se dieron cuenta que su forma de convivir no es tan irracional como desde occidente se ha enjuiciado. Frente a la crisis ecológica que azota a nivel planetario, la producción de la miseria, el empobrecimiento, el aumento del individualismo, el consumismo, el extractivismo, las transnacionales de la industria tóxicaquímica-alimentaria, etc. Las micropolíticas de la cercanía dejan de ser irracionales volviéndose alternativas "más racionales".

Cuando se ve desde las periferias o desde las fronteras este mundo basado en el pensamiento moderno eurocentrado, capitalista y patriarcal, aparece literalmente como "irracional". Cuando se cosifica, explota y mercantiliza la vida, se siente el espíritu empobrecido e instrumentalizado de la racionalidad moderna occidental.

Se insiste en que no se trata de expoliar sino de dejarse inspirar por otros modos de vivir en diálogo con la memoria histórica contextualizada en nuestros momentos actuales. La apuesta por la reciprocidad, como principio de acción no sólo entre integrantes de la comunidad o entre comunidades, también con la Tierra y el territorio, así:

"La reciprocidad no es lo mismo que intercambio de posesiones. No es: "me das y te doy", [sino] una manera de relación ética. Tampoco es dictadura impositiva a partir de amenazas físicas y/o afectivas... Los y las integrantes de la comunidad tienen apego entre sí -no por sangre o genes, sino por historia, memoria, territorio, valores, expectativas-. El Vivir Bien del hermano o la hermana de la comunidad es una responsabilidad y un deseo de todas y todos. Así mismo, cuando una persona comunitaria brinda a otra un bien concreto o simbólico, lo hace desarrollando su propio don y habilidad de brindar. Esto le alegra a la vez que le enaltece éticamente y le asegura que cuando ella -él- lo requiera estarán disponibles los bienes materiales y simbólicos para su Vivir Bien" (Feministas comunitarias, citadas en Gargallo, 2014: 188).

Siendo la reciprocidad más que un mero "me das-te doy" sino una relación ética, política, cultural, educativa, etc. para la imaginación y creación de la vida que queremos con-vivir nos preguntamos ¿Nosotras, recíprocas?

\subsection{Dislocación colonial: posicionamientos decoloniales}

Nos sigue resultando necesario voltear la mirada hacia la memoria histórica rescatando para el análisis crítico decolonial algunas claves de la negación, invisibilización, silenciamiento y desprecio de raíz colonial. Habrá que recordar que la Conquista de América fue ante todo “[...] una tremenda carnicería. Los conquistadores españoles, pos su escaso número no podían imponer su dominio sino aterrorizando a la población indígena” (Mariátegui, 1928:9). 
Una micropolítica de la cercanía necesita del conocimiento y cuidado de cada persona y de la comunidad. Volver a los orígenes históricos, no como un ejercicio nostálgico, sino como un posicionamiento político de mujeres con agencias propias. Nos inspiramos en el feminismo decolonial porque:

"Ante todo y sobre todo una apuesta epistémica. Se trata de un movimiento en pleno crecimiento y maduración que se proclama revisionista de la teoría y la propuesta política del feminismo dado lo que considera su sesgo occidental, blanco y burgués. El feminismo decolonial elabora una genealogía del pensamiento producido en los márgenes por feministas, mujeres, lesbianas y gente racializada en general y dialoga con los conocimientos generados por intelectuales y activistas comprometidos con desmantelar la matriz de opresión múltiple asumiendo un punto de vista no eurocentrado" (Espinosa, 2014: 184).

Los feminismos decoloniales, toman como referencia al feminismo negro y de color argumentando que no se puede explicar la opresión de la gran mayoría de mujeres desde una mirada que atienda sólo al género, complejizando los distintos sistemas de opresión y sus intersecciones: raza, clase, heterosexismo, nacionalidad, procedencia, etc. Este giro feminista se hace una crítica a la categoría universal de "mujer" dejando en evidencia la subalternidad y la ahistoricidad desde donde han sido teorizadas, nombradas y gestionadas "las otras mujeres noblancas", heterosexuales, clase media, residentes legales, etc. Nos sentimos tan involucradas en la explicación que hace el feminismo decolonial, porque pone en la mesa la crítica al feminismo blanco occidental heterosexual dicho y hecho por mujeres blancas de clase media y difundido en la universidad.

Las aportaciones de Lugones (2008) en los feminismos decoloniales es fundamental. Explica como la construcción de las categorías "mujer", por ejemplo, sin especificaciones tiene un sentido racista ya que parte categóricamente del grupo dominante de mujeres blancas burguesas heterosexuales. Dice además que la intersección interpreta erróneamente a las mujeres de color haciendo prevalecer el pensamiento categorial dominante. Para entender la intersección de raza y género hay que comprender el poder capitalista eurocentrado y global ya que está organizado en el sistema mundo-colonial de género:

"En este proyecto, llevo a cabo una investigación que acerca dos marcos de análisis que no han sido lo suficientemente explorados en forma conjunta. Por un lado, se encuentra el importante trabajo sobre género, raza y colonización que constituye a los feminismos de mujeres de color de Estados Unidos, a los feminismos de mujeres del Tercer Mundo, y a las versiones feministas de las escuelas de jurisprudencia Lat Crit y Critical Race Theory. Estos marcos analíticos han enfatizado el concepto de interseccionalidad y han demostrado la exclusión histórica y teóricopráctica de las mujeres no-blancas de las luchas liberatorias llevadas a cabo en el nombre de la Mujer. El otro marco es el introducido por Aníbal Quijano y que es central a sus análisis del patrón de poder global capitalista. Me refiero al concepto de la colonialidad del poder, que es central al trabajo sobre colonialidad del saber, del ser, y 
decolonialidad. Entrelazar ambas hebras de análisis me permite llegar a lo que esto llamando, provisoriamente, "el sistema moderno-colonial de género" (Lugones, 2008: 77).

Llevando la producción teórica a la práctica, quisimos evidenciar con estrategias de producción de conocimientos situados y encarnados el predominio del modelo colonial de la mujer como sujeta blanca burguesa heterosexual benefactora de privilegios que legitiman y custodian los feminismos hegemónicos:

“QQuiénes son las que están llamadas pagar el precio de la liberación de unas cuantas? Y de ahí sale que las que se benefician de este tipo de mirada feminista moderna y occidental son un grupo, las que están en lugar de privilegio, es decir, las blancas burguesas, las que están en un lugar de privilegio de raza y clase" (Espinosa, 2014: 26).

En nuestro espacio de vivencia compartida nos preguntamos ¿Desde qué privilegios hablamos, nombramos, imaginamos, queremos-hacer? ¿Tierrosas pretende hacer crítica a cómo se producen y construyen "las mujeres subalternas"? ¿Cómo y quiénes producen los modelos legitimados de mujeres libres, autónomas, empoderadas? ¿Todas podemos llegar a vivir esas vidas "liberadas" o "emancipadas" como predican las feministas académicas?:

"Obviamente cuando las mujeres blancas se politizan y llegan al feminismo, ellas terminan teorizando el lugar de opresión que ellas tenían dentro de un sistema que por otro lado las colocaba en lugar de poder o dentro de las clases dominantes. A ellas les fue imposible ver como eso se relacionaba con la clase y con la raza ... no nos queda más que decir que ese no es un análisis suficiente para la mayoría de nosotras, ni que incluso oculta y por tanto actúa en beneficio de unas y en detrimento de la gran mayoría" (Espinosa, 2014: 26).

El feminismo decolonial por el que nos sentimos inspiradas aporta al desarrollo de una epistemología surgida desde Abya Yala, por eso una de los primeros aspectos de las cuestiones que se quiere es potenciar la crítica al universalismo inspiradas por el blackfeminist, el feminismo de color y las feministas afrodescendientes:

"Si bien la epistemología feminista, con autoras como Evelyn Fox Keller, Donna Haraway, Sandra Harding, sólo por nombrar algunas, ha estado preocupada por analizar la pretensión de objetividad y universalidad, así como el androcentrismo en las ciencias (...) esta crítica ha mostrado sus límites al no poder articularse efectivamente a un programa de descolonización y desuniversador del sujeto mujeres del feminismo" (Espinosa, 2014: 8-9).

Las epístemes feministas clásicas producidas por mujeres blanco burguesas han hecho eco de las voces de las subalternas restando potencias, resistencias y disidencias incluso despolitizando las luchas propias. Las palabras referenciales no alcanzan a expresar lo que se vive cuando atraviesa la raza, clase, género, nacionalidad, etc. en las propias carnes, de manera que en 
sus haceres reproducen los mismos problemas que critican a las ciencias universales androcéntricas, antropocéntricas, eurocéntricas marcando ajenidades, "dando la voz".

El viraje epistémico para construir con nuestras propias experiencias antirracistas, antisexistas, antipatraricales, anti-desarrollistas, etc. y con nuestras propias voces sin intermediarias ni traducciones: "La apuesta obliga a abandonar y cuestionar activamente esta pretensión de unidad en la opresión entre las mujeres” (Espinosa, 2014: 12).

\section{Locus de investigación}

Tierrosas, locus amoenus ${ }^{9}$ creado por mujeres-migradas-racializadas en las arenas de la academia y posicionadas como sujetas de nuestro propio quehacer y con agencias propias organizamos una investigación militante. Nosotras, no consideramos a Tierrosas como objeto ni pretexto de investigación sino como lugar propicio donde todas las sujetas forman parte de una misma dinámica viva, compleja, cambiante y contradictoria.

En nuestras primeras experiencias como investigadoras militantes no pretendímos "hacer ciencia" que desperdicie nuestras experiencias, sentimientos, deseos, reciprocidades, sino queremos hacer vida que merezca la alegría con-vivirse en los lugares donde vivimos.

Tierrosas es locus situado que empieza formulándose existencialmente en el lugar donde aparece la pregunta, es decir, que no se ubica por abstracción o epojé fuera del problema, sino que desde nuestros cuerpos racializados y en el territorio donde fue posible encontrarnos. Interactuamos en conversatorios-taller informales entre amigas y compañeras de utopías y rebeldías proyectando cruces de caminos creativos.

Encontrándonos, actualmente (año 2017) en otro momento como compañeras e investigadoras podemos decir que Tierrosas nos ha permitido llevar a la práctica una minka ${ }^{10} \mathrm{de}$ pensamientos, sentires, dudas, experiencias, emociones, investigaciones académicas, etc. Tres compañeras, siguiendo cada una un camino singular pero hilado por una complicidad y amistad política hemos investigado en y desde Tierrosas algunas cuestiones de interés propio y común: un Trabajo Final de Grado, un Trabajo Final de Máster y una Tesis Doctoral todos en la Universitat de València, además de unas vivencias y amistades políticas de incalculable valor.

\footnotetext{
${ }^{9}$ Locus amoenus como un lugar bello, ameno, propicio para llevar acabo la generación de pensamientos, acciones, afectos y espiritualidades alternativas a la modernidad occidental, al capitalismo y al patriarcado. ${ }^{10}$ La minka es una práctica precolombina de trabajo comunitario o colectivo voluntario, de carácter recíproco y solidario sin ánimo de lucro, en beneficio de una persona, comunidad o colectivo. Actualmente vigente en varios países latinoamericanos: Colombia, Perú, Ecuador, Bolivia, Chile, Paraguay.
} 


\section{Trayectoria de la investigación}

Nuevamente, nos dejamos inspirar por la metodología feminista comunitaria donde las apachetas $^{l 1}$ como lugares y momentos del camino son propicios para reflexionar, sacudirse, celebrar, ofrendar, amar: "elegimos la figura de las apachetas no por su excentricidad, sino para explicar que son una mezcla de muchas cosas, no es solo racional, o ritual, so muchas cosas juntas y esa es la experiencia de llegar a una apacheta” (Paredes y Guzmán 2014: 88).

Hemos tomado como referencia los cinco campos de acción propuestas por las feministascomunitarias (cuerpo, espacio, tiempo, movimiento, memoria), y aprendiendo paso a paso a descolonizar nuestros feminismos y creando simbólicamente apachetas.

\section{a) Apacheta encuentros comunes}

Se comentó anteriormente que la colectiva empezó a germinarse en un locus singular y contingente en conversatorios informales entre amigas y compañeras universitarias, mujeresmigradas-racializadas, haciendo comunidad como construcción política, ética, ecológica que supera el individualismo moderno y sus manifestaciones más rancias en las mareas neoliberales.

En los conversatorios informales retomamos más de una vez la pregunta vectora ¿Qué vida queremos con-vivir? como aspecto fundamental del camino y tiempo circular de la investigación.

\section{b) Apacheta cuerpos-territorios}

Como feministas parte de nuestras luchas consistió en dinamitar los estigmas que históricamente el sexismo, el racismo, el colonialismo, el machismo ha perpetuado haciendo del cuerpo el medio por excelencia para sustentar violencias, sumisiones, opresiones y servilismos:

\footnotetext{
"Tapar el propio cuerpo, esconderlo bajo vestidos o kilos de grasa, defender el derecho a no mostrarlo, enojarse frente a la desnudez de otras, aceptar de la crítica feminista exclusivamente la crítica al uso del cuerpo femenino para la publicidad que, efectivamente, cosifica a las mujeres retratadas y las funcionaliza para despertar el deseo de posesión - de otros cuerpos, de otras cosas- por parte del colectivo masculino, son complicadas racionalizaciones y acciones que no pueden ser igualadas, pero que engloban -todas- el rechazo a un cuerpo socialmente construido para la invisibilidad y la sumisión, un cuerpo racializado" (Gargallo, 2014: 246).
}

Hacer memoria implica "saber de dónde somos, adónde vamos, cómo venimos y cómo vamos. Valorar nuestros saberes y conocimientos” (Paredes y Guzmán, 2014: 97).

\footnotetext{
${ }^{11} \mathrm{La}$ apacheta, del quechua: apachita, es un montículo de piedras colocadas en forma cónica una sobre la otra, como ofrenda a la Pachamama, práctica realizada por los pueblos originarios andinos.
} 
Quisimos hacer dialogar nuestras memorias que atraviesan nuestros cuerpos racializados. Confrontar los racismos y a la blanquitud, la marginación y el empobrecimiento, la ridiculización y mofa de nuestros cuerpos-territorios, cosmovisiones y lenguas:

"El cuerpo que se abraza con el "territorio tierra", el cual implica un lugar significado e histórico donde habita la memoria larga de los pueblos, un territorio de recuperación por la expropiación colonial, la usurpación de modelos organizativos impropios, su imposición mercantilista de propiedad privada, remitido a ser parte del estado nación colonial pero también en defensa ante el auge del neoliberalismo" (Gargallo, 2014: 154).

Reconocer los cuerpos en todo su esplendor y desembarazarnos a la vez del racismo y colonialidad heredada de nuestros lugares de procedencia.

\section{c) Apacheta rituales $\mathbf{y}$ artificios}

Tomamos a los rituales y las expresiones creativas devenidas en los mismos como instrumentos de lucha que permiten escapar y crear otros modos de sentipensar y expresar. Las experiencias que tienen lugar en el ritual, conllevan arte como conversión de la vida cotidiana. Fuera del orden contribuyen a la creación de acontecimientos lúdicos, es decir, un curioso tiempo extraordinario, entre la técnica, la habilidad, y los artificios.

Herederas sin testamento de la modernidad eurocéntrica, hemos hecho gala de nuestra capacidad de ritualizar nuestras prácticas que desbordan los límites de la racionalidad moderna occidental. Desarrollamos rituales de comensalidad, de limpias, de agradecimiento como la ch'alla, etc., en tiempos extraordinarios de ruptura con la racionalidad cognoscitiva occidental.

Decía Deleuze (1989: 157) "los acontecimientos se efectúan en nosotros, nos esperan y nos aspiran, nos hacen señales", el hacer rituales y performances como parte de los acontecimientos nos fueron mostrando señales para devenir el locus. ¿Qué estamos haciendo para cambiar las reglas del juego? ¿Cómo romper la obstinación cartesiana?:

"El encuentro con una señal se produce en la delgada línea entre lo que ya existe y lo que todavía no ha tenido lugar. Este encuentro, nos arrastra hacía caminos aún impensables para nosotros, desplaza nuestra mirada de "aquello que sabemos", de la manera de representarnos una situación, un proyecto, un trozo de vida. "Salir de" para "adoptar otro punto de vista" (Vercauteren, Crabbé y Müller, 2010:41).

Tierrosas devino como una irrupción a los feminismos hegemónicos que veníamos aprendiendo, los rituales y los artificios, nos permitieron dejar fluir potencialidades sui generis, desobediencia creativa y establecer como predilecta a la relación ritual donde los símbolos fueron meras representaciones, sino la presencia vivencial en su densidad celebrativa semántica. 


\section{Evaluaciones-estimaciones sin concluir}

Para la evaluación hicimos converger dos estrategias interrelacionadas como un modo de romper con la evaluación dualista encaminada hacia la valoración al objeto ajeno al sujeto, investigador-investigado, y consideramos pertinente realizar estimaciones a dos bandas: entre nosotras y a modo personal.

La primera implicó procesos reflexivos comunitarios a través de diferentes técnicas e instrumentos como fueron: las producciones artísticas, rúbricas valorativas diseñadas para cada conversatorio-taller, etc., y la segunda implicó procesos reflexivos individuales como las autobiografías orales, etc.

En coherencia con lo planteado se propuso que en los procesos de evaluación y estimación se tomaran en cuenta desde distintas perspectivas críticas a las dislocaciones en el intento de crear otros modos de estimación valoración y apostamos por formular, en clave de sumak kawsay, lo que no quisimos concluir.

El sumak como lo excelente, lo magnífico, la plenitud y en relación con las prácticas está integrado por la conjunción de cuatro fuentes que orden y significación del buen vivir: el kawsay que es estar estando, tiene que ver con lo dinámico y cambiante y la vida en excelencia espiritual y material; munay con la voluntad, los afectos, la necesidad de apasionarse; ruray se refiere a la experiencia, las creaciones, a la organización del trabajo; yachay entraña la sabiduría y los conocimientos colectivos, el filosofar, los aprendizajes permanentes (Macas, 2010).

\section{Figura 1. Matriz filosófica de los procesos de evaluación-estimación basados en el Sumak Kawsay}

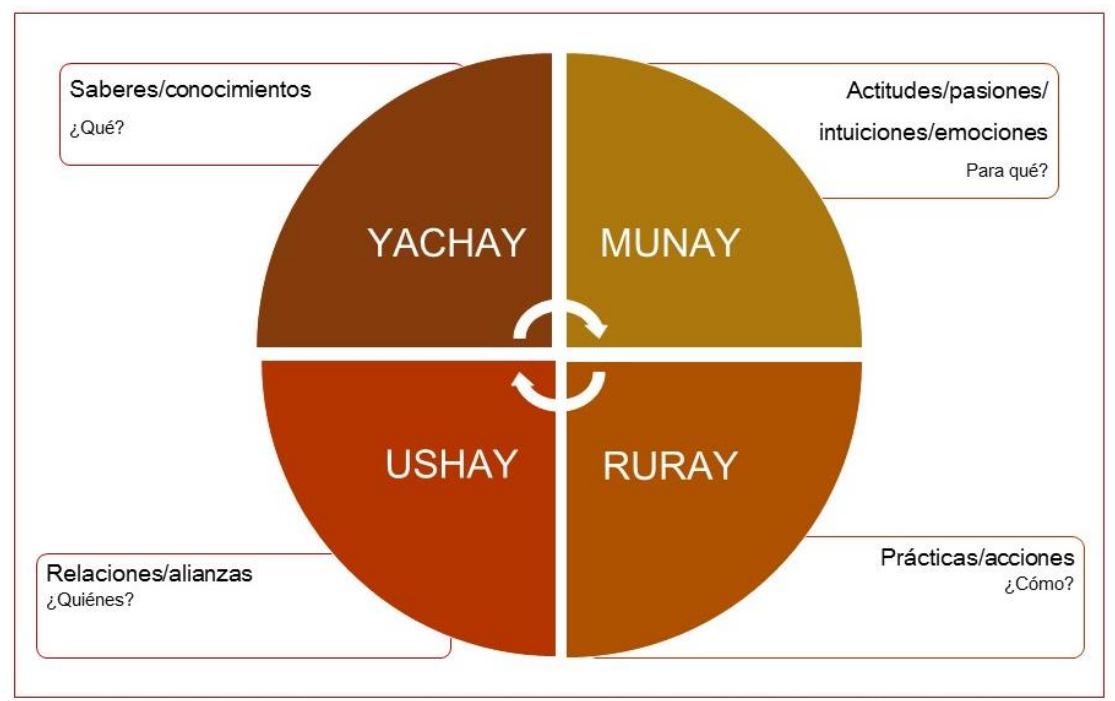

Fuente: Elaboración propia 
Sabiendo que la vida que merece la alegría vivir la hacemos en y desde las fronteras y al mismo tiempo viviendo sin ellas, sintiendo y comprendiendo situada y encarnadamente lo que implica y significa vivir en las borderlands en los cruces de caminos como dirá Gloria Anzaldúa (2016), aceptamos que el sumak kawsay/suma qamaña es imposible en nuestros contextos y en los modos de vida capitalistas neoliberales, heteronormados, racistas, ecocidas, etc., sin embargo quisimos lo imposible en y para nuestra micropolítica.

\section{BIBLIOGRAFÍA}

- Anzaldúa, Gloria (2016): Borderlands/La Frontera: The New Mestiza. Madrid:Capitán Swing Libros.

- Bautista, Juan José (2014): ¿Qué significa pensar desde América Latina? Madrid: Akal.

- Espinosa-Miñoso, Yuderkys (2014): "Una crítica descolonial a la epistemología feminista crítica”. En: El Cotidiano, nº. 184, marzo-abril, pp. 7-12. Universidad Autónoma Metropolitana Unidad Azcapotzalco Distrito Federal, México.

- Feminismo Comunitario (2010): "Pronunciamiento del Feminismo Comunitario en Tiquiyapa, en la Cumbre de los Pueblos sobre el Cambio Climático”. Disponible en: http://perspectives.apps01.yorku.ca/2010/05/08/pronunciamiento-del-feminismo-comunitariolatinoamericano-en-la-conferencia-de-los-pueblos-sobre-cambio-climatico/ [20/01/2017].

- Gargallo, Francesca (2014): Feminismos desde Abya Yala. Ideas y proposiciones de las mujeres de 607 pueblos en nuestra América. México: Corte y Confección.

- Gilles Deleuze (1989): Lógica del sentido. Barcelona, Paidós.

- Lugones, María (2008): “Colonialidad y género”. En: Tabula Rasa, Revista de Humanidades, $\mathrm{n}^{\circ}$. 9, julio-diciembre, pp. 73-101. Disponible en: http://revele.com.veywww.redalyc.org/articulo.oa?id=39600906 [20/01/2017].

- Gobierno de Bolivia (2009): “Constitución del Estado Plurinacional de Bolivia”. Disponible en: http://www.harmonywithnatureun.org/content/documents/159Bolivia\%20Consitucion.pdf [20/01/2017].

- Gobierno de Ecuador (2008): “Constitución de la República del Ecuador”. Disponible en: http://www.asambleanacional.gov.ec/documentos/constitucion_de_bolsillo.pdf [20/01/2017].

- Mariategui, José Carlos (1982): La cuestión del indio. Disponible en: http://documents.routledge-

interactive.s3.amazonaws.com/9780415854375/Document\%205.4\%20Mariategui\%20Spanish.p df [20/01/2017].

- Macas, Luis (2010): "El Sumak Kawsay Yuyay". En: Antonio Luis Hidalgo-Capitán, Alejandro Guillén García y Nancy Deleg Guazha (eds.): Antología del pensamiento indigenista ecuatoriano sobre Sumak Kawsay. Huelva: CIM, Fiucuhu, Pydlos, pp. 169-192. Versión online disponible

en: 
http://dspace.ucuenca.edu.ec/bitstream/123456789/21745/1/Libro\%20Sumak\%20Kawsay\%20Y uyay.pdf [20/01/2017].

- Malo, Marta (2004): “Prólogo". En: Marta Malo (ed.): Nociones Comunes. Experiencias y ensayos entre investigación y militancia. Madrid: Traficantes de Sueños, pp. 13- 39. Versión online Disponible en: http://www.traficantes.net/sites/default/files/pdfs/Nociones\%20comunesTdS.pdf [20/01/2017].

- Martínez Yánez, Esperanza (2014): La naturaleza entre la cultura, la biología y el derecho. Quito: Instituto de estudios ecologistas del tercer mundo, Abya-Yala. Versión online disponible en: http://www.rebelion.org/docs/187943.pdf [20/01/2017].

- Paredes, Julieta y Guzmán, Adriana (2014): El tejido de la Rebeldía. ¿Qué es el feminismo comunitario? La Paz: Mujeres Creando Comunidad.

- Pérez Orozco, Amaya (2013): "La sostenibilidad de la vida en el centro... ¿y eso qué significa?"- Comunicación presentada en IV Congreso de Economía Feminista. Celebrado en Carmona-Sevilla, los días 3,4 y 5 de octubre. Disponible en: http://riemann.upo.es/personalwp/congreso-economia-feminista/files/2013/10/PerezOrozco_Amaia.pdf [20/01/2017].

- Pérez Orozco, Amaya (2014). Subversión feminista de la economía. Aportes para un debate sobre el conflicto capital-vida. Madrid: Traficantes de sueños.

- Precarias a la deriva (2004): "De preguntas, ilusiones, enjambres y desiertos. Apuntes sobre investigación y militancia desde Precarias a la deriva (Madrid)". Marta Malo (ed.): Nociones Comunes. Marta Malo (ed.): Nociones Comunes. Experiencias y ensayos entre investigación y militancia. Madrid: Traficantes de Sueños, pp. 81- 389. Versión online disponible en: http://www.traficantes.net/sites/default/files/pdfs/Nociones\%20comunes-TdS.pdf [20/01/2017].

- Rivera Cusicanqui, Silvia (2015): “Glosario de términos en otras lenguas". En Sociología de la imagen. Miradas ch 'ixi desde la historia andina. Madrid: Traficantes de Sueños, pp. 321-336.

- Vercauteren, David; Crabbé, Oliver y Müller, Thierry (2010): Micropolíticas de los grupos. Para una ecología de las prácticas colectivas. Madrid: Traficantes de sueños. 